\title{
Aktivitas Antioksidan dan Kandungan Senyawa Fenolik Makroalga Coklat Sargassum sp.
}

\author{
Sri Sedjati*, Suryono, Adi Santosa, Endang Supriyantini dan Ali Ridlo \\ Departemen IImu Kelautan, Fakultas Perikanan dan Ilmu Kelautan, Universitas Diponegoro \\ JI. Prof. Soedarto, SH. Kampus UNDIP Tembalang, Semarang 50275 \\ Email : sedjati69@gmail.com
}

\begin{abstract}
Present research was to evaluated the antioxidant activities of extracts from macroalga Sargassum sp. In this study, seven filtrates from maceration (methanol pa and technical grade, ethanol pa and techinal grade, methanol technical grade 50\%, infused hot water, boiled water) were analyzed for total phenolic compound (TPC) and for antioxidant activities (DPPH method). The results revealed that the water filtrates possessed more TPC and antioxidant antivity than alcoholic filtrates, and the highest was water filtrate from boiled Sargassum sp. (TPC $=1,36 \pm 0,01 \mathrm{mgGAE} / \mathrm{g}$ dry weight; \% inhibtion DPPH $=81,35 \pm 0,42 \%$ ). The high positive correlation between TPC and antioxidant activity ( $r=0.99$ ) suggested that phenolic compound were the mayor antioxidant components. The effect of TPC (dependent variable) on DPPH radical inhibition (independent variable) with regression formula $y=55,39 x+5,18$.
\end{abstract}

Keywords : Sargassum sp., phenolic compound, antioxidant activity.

Abstrak

Penelitian ini mengevaluasi potensial aktivitas antioksidan ekstrak Sargassum sp. Pada kajian ini, 7 filtrat hasil maserasi (metanol pa dan teknis, etanol pa dan teknis, metanol teknis $50 \%$, perendaman air panas/hot infused, dan perebusan dengan air) dianalisis kandungan total fenoliknya (TPC) dan aktivitas antioksidannya (metoda DPPH). Hasil penelitian ini mengungkapkan bahwa filtrat air memiliki kandungan TPC dan antioksidan yang relatif lebih tinggi dibanding filtrat alkohol dan yang tertinggi adalah filtrat hasil perebusan Sargassum sp. ( $\mathrm{TPC}=1,36 \pm 0,01 \mathrm{mgGAE} / \mathrm{g}$ berat kering; inhibisi DPPH $=81,35 \pm 0,42 \%$ ), Korelasi positif yang tinggi antara TPC dan aktivitas antioksidan ( $r=0.99)$ menunjukkan bahwa kandungan senyawa fenolik merupakan komponen utama yang menghasilkan aktivitas antioksidan. Pengaruh TPC (variabel bebas) terhadap inhibisi radikal DPPH (variabel terikat) sesuai dengan persamaan regresi $y=55,39 x+5,18$.

Kata kunci : Sargassum sp., senyawa fenolik, aktivitas antioksidan.

\section{PENDAHULUAN}

Alga laut diketahui banyak mengandung senyawa bahan alam yang bersifat bioaktif. Beberapa senyawa di antaranya memiliki efek "pharmaceutical" sekaligus berfungsi sebagai kosmetik, sehingga muncul istilah "cosmeceutical". Arti dari istilah tersebut menunjukkan karakter suatu produk yang berada pada katagori kosmetik dan obat (drugs) (Agatonovic-Kustrin et al., 2016). Ekstrak alga laut banyak digunakan untuk bahan perawatan kulit, karena dapat merangsang regenerasi kulit, mengurangi kerutan, mengurangi stres oksidatif dan meningkatkan sintesis kolagen (Fitton et al., 2016). Produk perawatan kulit "cosmeceutical" harus dapat memperbaiki fungsi dan struktur kulit, selain dapat meningkatkan penampakan kulit (Wang et al., 2015)

Menurut Fitton et al. (2016), sebuah perusahaan bioteknologi asal Australia, Marinova telah mengembangkan 
senyawa bahan alam dari alga coklat Undaria pinnatifida dan Fucus fesiculosus sebagai bahan kosmetik. Esktrak Undaria pinnatifida (fukoidan $89,6 \%$, polifenol $<2 \%$, karbohidrat netral $48,8 \%$, sulfat $27,4 \%$, kation 9\%) terbukti bersifat skin protecting, sedangkan ekstrak Fucus fesiculosus(fukoidan 58,6\%, polifenol 33,7\%, karbohidrat netral $43,7 \%$, sulfat $10,1 \%$, kation 3\%) dapat mereduksi noda-noda penuan, meningkatkan kecerahan kulit dan sebagai pelembab sekaligus pelembut kulit.

Sargassum sp., merupakan salah satu alga coklat yang kaya bahan bioaktif, di antaranya: alginat, fukoidan, fucoxantin, dan phlorotannin (senyawa fenolik yang khas pada alga coklat). Senyawa-senyawa tersebut banyak diaplikasikan untuk produk kosmetik perawatan kulit, karena bisa berfungsi sebagai bahan pengemulsi (emulsifier), pemutih kulit (skin whitening), pencegah penuaan (anti-ageing), anti kerutan (anti-wrinkle), pencegah alergi, maupun sebagai antioksidan.

Menurut Uppala (2015), ekstrak alga dapat digunakan dalam formula kosmetik dengan 2 tujuan yang berbeda, sebagai eksipien (emulsifier atau stabilizer) dan sebagai bahan bioaktif terapeutik (antioksidan, antibakteri, anti-inflamasi, dIII).

Salah satu alga coklat, Sargassum duplicatum merupakan salah satu jenis rumput laut coklatdari Indonesia yang berpotensi sebagai antioksidan karena mengandung zat-zat aktif seperti fukoidan dan komponen fenolik (Lim et al., 2002). Jenis komponen fenolik yang banyak dijumpai pada rumput laut coklat adalah phlorotanin yang berkisar antara $0.74 \%$ sampai $5.06 \%$ (Samee et al., 2009).

Pemicu utama masalah penuaan/kerusakan kulit adalah stres oksidatif, yang terjadi secara alamiah dan dipicu faktor lingkungan (seperti radiasi sinar matahari/UV, asap/polusi udara). Menurut Fitton et al., 2016, struktur sel alga mempunyai kemiripan dengan struktur kulit manusia, sehingga dapat diasumsikansenyawa bahan alam yang ditemukan di sel alga dapat bermanfaat bagi kulit. Alga laut merupakan organisme fotosintetik yang sering terpapar sinar matahari dan oksigen tinggi, keduanya merupakan pemicu terbentukknya radikal bebas dan agen pengoksidasi (oksidator) yang kuat. Radikal bebas dan oksidator berpotensi merubah struktur dan fungsi sel, namun pada kenyataannya sel alga tidak mengalami kerusakan. Fenomena ini membuktikan bahwa alga laut memiliki mekanisme pertahanan anti oksidatif dan mengandung senyawa antioksidan.

Berdasarkan peluang tersebut, perlu dilakukan penelitian tentang kandungan senyawa-senyawa tersebut dan melihat potensi antioksidannya. Penelitian ini merupakan langkah awal untuk pengembangan bahan alami laut, khususnya ekstrak Sargassum sp. untuk perluasan produk kelautan, memasuki dunia industri kosmetik.

Tujuan dari penelitian ini adalah untuk menentukan potensi antioksidan Sargassum sp. dan menganalisis kandungan senyawa fenoliknya (total phenolic content). Tolak ukur aktivitas antioksidan ditentukan berdasar kemampuannya sebagai penangkal radikal bebas (free radical scavenging activity).

\section{MATERI DAN METODE}

Materi utama yang digunakan adalah makroalga coklat Sargassum sp. yang diperoleh dari perairan Teluk Awur, Jepara. Materi pendukung berupa kertas saring, aluminium foil, bahan kimia untuk proses ekstraksi dan uji/analisis kimiawi. Bahan kimia tersebut meliputi :Etanol dan metanol (pro analisis dan teknis), aquades, natrium karbonat $\left(\mathrm{Na}_{2} \mathrm{CO}_{3}\right)$, asam galat, dan asam askorbat/vitamin C.Reagen berupa DPPH (2,2-diphenyl-1picrylhydrazyl), dan Follin-Ciocalteau.

Alat-alat yang digunakan berupa pralatan gelas (gelas piala, erlenmeyer, gelas ukur, corong, tabung reaksi, vial, pengaduk), neraca analitik, mikropipet, hot platemagnetic stirrer, magnetic bar,vortex/homogenizer, cuvet kaca, spektrofotometer UV-Vis. 
Preparasi sampel sebelum digunakan penelitian dimulai dari perendaman Sargassum sp. segar dengan air tawar, pencucian dengan air mengalir dan pengeringan. Pengeringan dilakukan dengan cara diangin-anginkan sampai kering, dihaluskan dengan blender, kemudian disimpan dalam wadah kedap udara.

Ekstraksi menggunakan metode maserasi. Sebanyak $1 \mathrm{~g}$ Sargassum sp. kering dilarutkan dengan $20 \mathrm{ml}$ pelarut (1:20). Pelarut yang digunakan adalah etanol (pa dan teknis), metanol (pa dan teknis), metanol teknis $50 \%$, dan aquades (panas/infused dan perebusan). Ekstraksi dilakukan dengan proses maserasi 24 jam pada suhu kamar (dikombinasi dengan pengadukan 30 menit menggunakan magnetic bar di awal maserasi). Perlakuan maserasi dengan air panas/infused menggunakan aquades panas $\left(100^{\circ} \mathrm{C}\right)$, sedangkan perlakuan perebusan dilakukan dengan memanaskan sampel menggunakan hot plate magnetic stirrer $\left(100^{\circ} \mathrm{C} ; \quad 30\right.$ menit, kemudian dimaserasi 24 jam pada suhu kamar. Hasil maserasi disaring menggunakan kertas saring (Whatman no.1). Filtrat disimpan menggunakan vial kecildibungkus aluminium foil dan dianalisis TPC (total phenolic content), dan RSA (free radical scavenging activity).

\section{Uji TPC (Total Phenolic Content)}

Penentuan TPC filtrat menggunakan reagen Folin-Ciocalteau, sesuai dengan metode Norra et al.(2016) dengan sedikit modifikasi. Masing-masing filtrat sebanyak $200 \mu \mathrm{l}$ dimasukkan dalam tabung reaksi kecil dan ditambah dengan $1 \mathrm{ml}$ reagen Folin-Ciocalteau (diencerkan 10 kali lipat dengan aquades). Setelah 5 menit dari proses pencampuran, ditambahkan $2 \mathrm{ml}$ natrium karbonat $\left(\mathrm{Na}_{2} \mathrm{CO}_{3} \quad 7,5 \% \mathrm{~W} / \mathrm{v}\right)$. Campuran dihomogenasi dengan vortex dan diinkubasi selama 120 menit pada suhu kamar. Absorbansi filtrat diukur pada panjang gelombang $765 \mathrm{~nm}$ dengan menggunakan Spektrofoto-meter (model Agilent Cary 60 UV-Vis.). Nilai TPC diekspresikan sebagai ekivalen mg asam galat (GAE)/g berat kering sampel.Kurva standar asam galat yang dipakai adalahy $=0,016 x+0,013\left(r^{2}=0,992\right)$. Kandungan total fenolik dihitung menggunakan rumus:

$$
\text { Total Fenolik }=\frac{a x V / 1000}{G}
$$

$$
\begin{aligned}
& \text { Keterangan } \\
& a \quad=\text { konsentrasi asam galat (mg/L) } \\
& \vee \quad=\text { volume total larutan uji (ml) } \\
& G \quad=\text { massa sampel }(\mathrm{g}) \\
& \begin{aligned}
1000 & \text { faktor konversi terhadap volume total } \\
& \text { larutan }(\mathrm{ml})
\end{aligned}
\end{aligned}
$$

\section{Uji RSA (Free Radical Scavenging Activity)}

Uji RSA dilakukan dengan metode DPPH (2,2-diphenyl-1-picrylhydrazyl). Uji DPPH menggunakan metode Norra et al. (2016). Masing-masing filtrat sebanyak 100 $\mu \mathrm{l}$ dimasukkan dalam tabung reaksi kecil ditambah dengan 2,9 ml DPPH (konsentrasi $0,004 \%$ dalam metanol). Setelah 120 menit masa inkubasi (suhu kamar dan kondisi tanpa cahaya), larutan diukur absorbansinya pada panjang gelombang serapan maksimum dari DPPH (515 nm). Persentase inhibisiradikal bebas DPPH dihitung menggunakan rumus:

$$
\text { In. DPPH }(\%)=\frac{(\text { A blanko }- \text { Asampel })}{\text { A blanko }} \times 100
$$

Keterangan

A blanko = Abs. DPPH tanpa sampel

A sampel $=$ Abs. sampel + DPPH

Kurva standar asam ascorbat yang dipakai adalah $y=3,93 x+7,82\left(r^{2}=0,907\right)$ dan potensi antioksidannya diekspresikan sebagai ekivalen mg asam ascorbat/ $g$ berat kering sampel.

\section{HASIL DAN PEMBAHASAN}

Kandungan total fenol Sargassum sp. dari Perairan Teluk Awur, Jepara berkisar dari $0,11 \pm 0,01 \mathrm{mgGAE} / \mathrm{g}$ sampai dengan $1,36 \pm 0,01 \mathrm{mgGAE} / \mathrm{g}$ berat kering. Pelarut air dapat menarik lebih banyak senyawa fenolik dibanding pelarut alkohol. Maserasi dengan pelarut metanol teknis 50\% dapat menarik senyawa fenolik sebesar $0,44 \pm 0,03$ $\mathrm{mgGAE} / \mathrm{g}$ berat kering, sedangkan dengan air panas (infused hot water) total fenoliknya meningkat menjadi 0,95 $\pm 0,03$ $\mathrm{mgGAE} / \mathrm{g}$ berat kering. Perebusan selama 30 menit (suhu $100^{\circ} \mathrm{C}$ ) dan 
dilanjutkan dengan proses maserasi 24 jam menghasilkan kandungan total fenolik tertinggi, yaitu 1,36 $\pm 0,01 \mathrm{mgGAE} / \mathrm{g}$ berat kering (Gambar 1).

Penelitian sejenis sudah dilakukan oleh Wai et al. (2015), total TPC Sargassum polycystum dari Sabah (Malaysia) yang diperoleh secara maserasi $50 \%$ etanol (1:10) selama 2 jam dengan suhu $65^{\circ} \mathrm{C}$ adalah $0,37 \pm 0,01 \mathrm{mgGAE} / \mathrm{g}$ berat kering. Ozgun (2015) meneliti beberapa makroalga coklat dari Teluk Iskenderun (Turki) yang dimaserasi dengan metanol

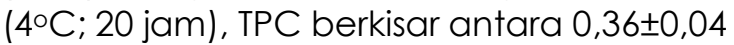
sampai 1,31 $\pm 0,03 \mathrm{mgGAE} / \mathrm{g}$ berat kering, dan yang tertinggi adalah TPC Sargassum schimperi.

Keberadaan senyawa ini menjadikan Sargassum polycystum memiliki potensi antioksidan lebih tinggi dibanding rumput laut Eucheuma denticulatum dan Kappahycus alvarezzi.
Hwang et al. (2010) juga meneliti Sargassum hemiphyllum (perairan Penghu County, Taiwan, namun diekstraksi dengan metode maserasi air panas. Ekstraknya memiliki potensi antioksidan $\left(\mathrm{IC}_{50}\right)$ sebesar $410 \mathrm{mg} / \mathrm{L}$.

Karakter pelarut yang dipakai untuk proses ekstraksi menentukan tipe senyawa fenolik yang terekstrak (Liyana-Pathirana \& Shahidi, 2005). Senyawa fenolik alga coklat secara alamiah bersifat bipolar, jadi bisa terdapat sebagai senyawa non polar sampai polar (Wei et al., 2003). Kombinasi alkohol dan air dapat mengambil golongan senyawa fenolik yang cenderung lebih polar, seperti flavonoid, catechin, rutin, dan quercetin (Spigno et al., 2007). Konsentrasi alkohol yang tinggi dapat mengekstrak pigmen, ataupun lemak, sehingga kadar fenol yang terambil relatif lebih kecil .Luo et al. (2010) juga meneliti tentang kandungan fenolik pada beberapa spesies genus Sargassum.

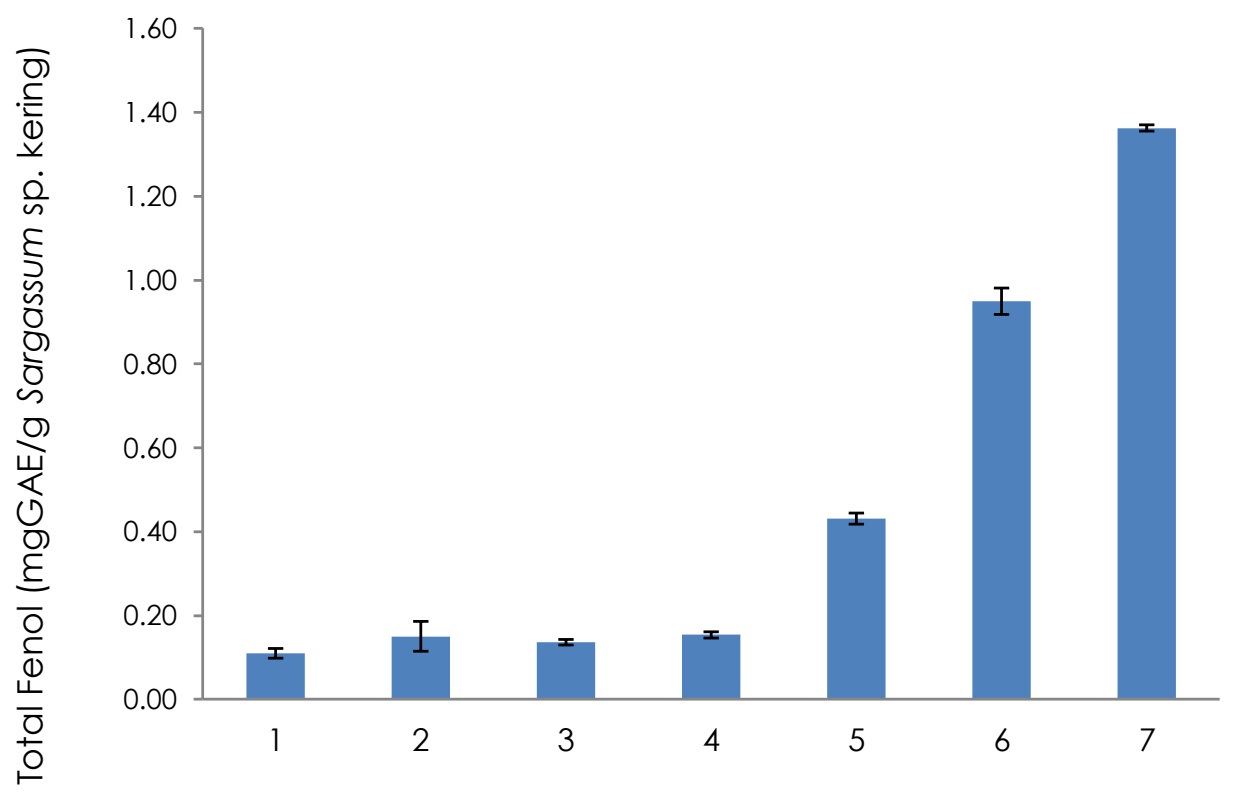

Filtrat Sargassum sp. dengan berbagai pelarut

Gambar 1. TPC Filtrat Sargassum sp.(1) metanol teknis ; (2) metanol pa. ; (3) etanolteknis ; (4) etanol pa. ; (5) metanol teknis 50\%; (6) air panas/infused; (7) perebusan 30 menit 


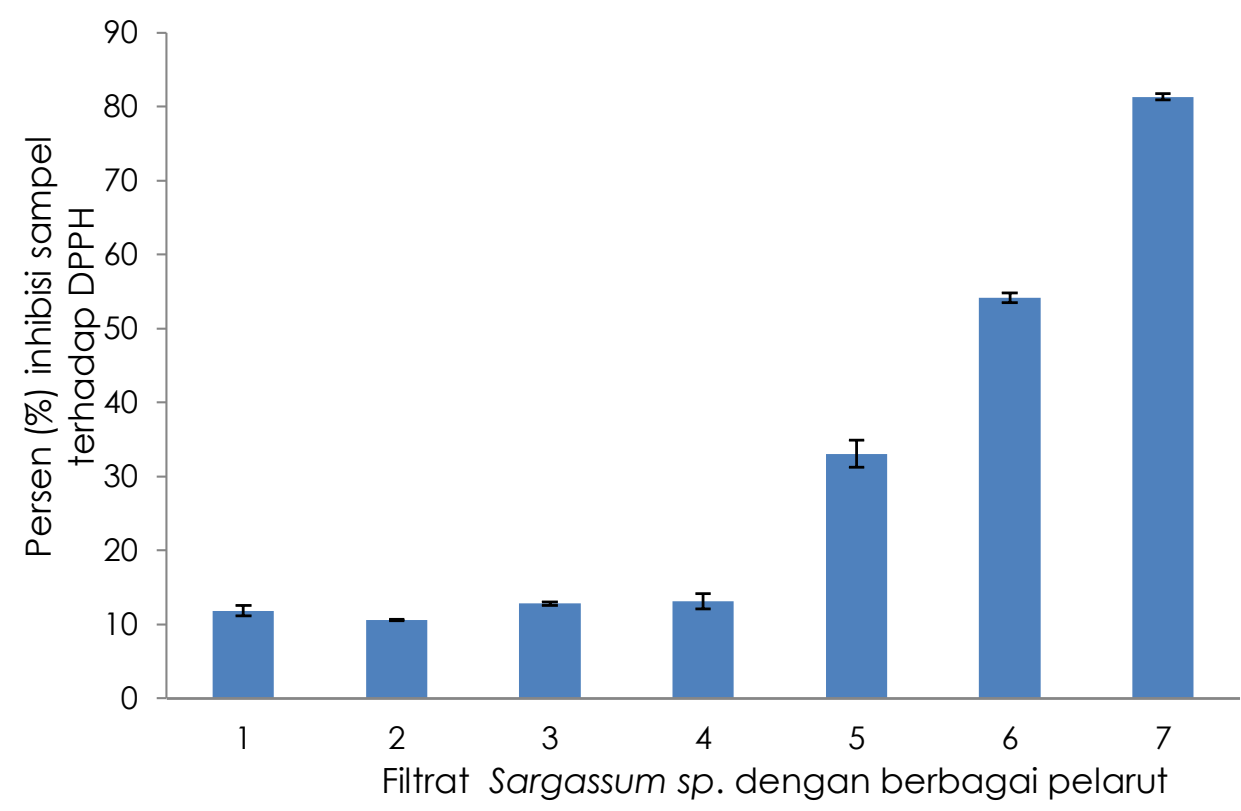

Gambar 2. Inhibisi (\%) Filtrat Sargassum sp. terhadap Radikal DPPH : (1) metanol teknis ; (2) methanol pa. ; (3) etanol teknis ; (4) etanol pa. ; (5) methanol teknis 50\%; (6) air panas/infused; (7) perebusan 30 menit

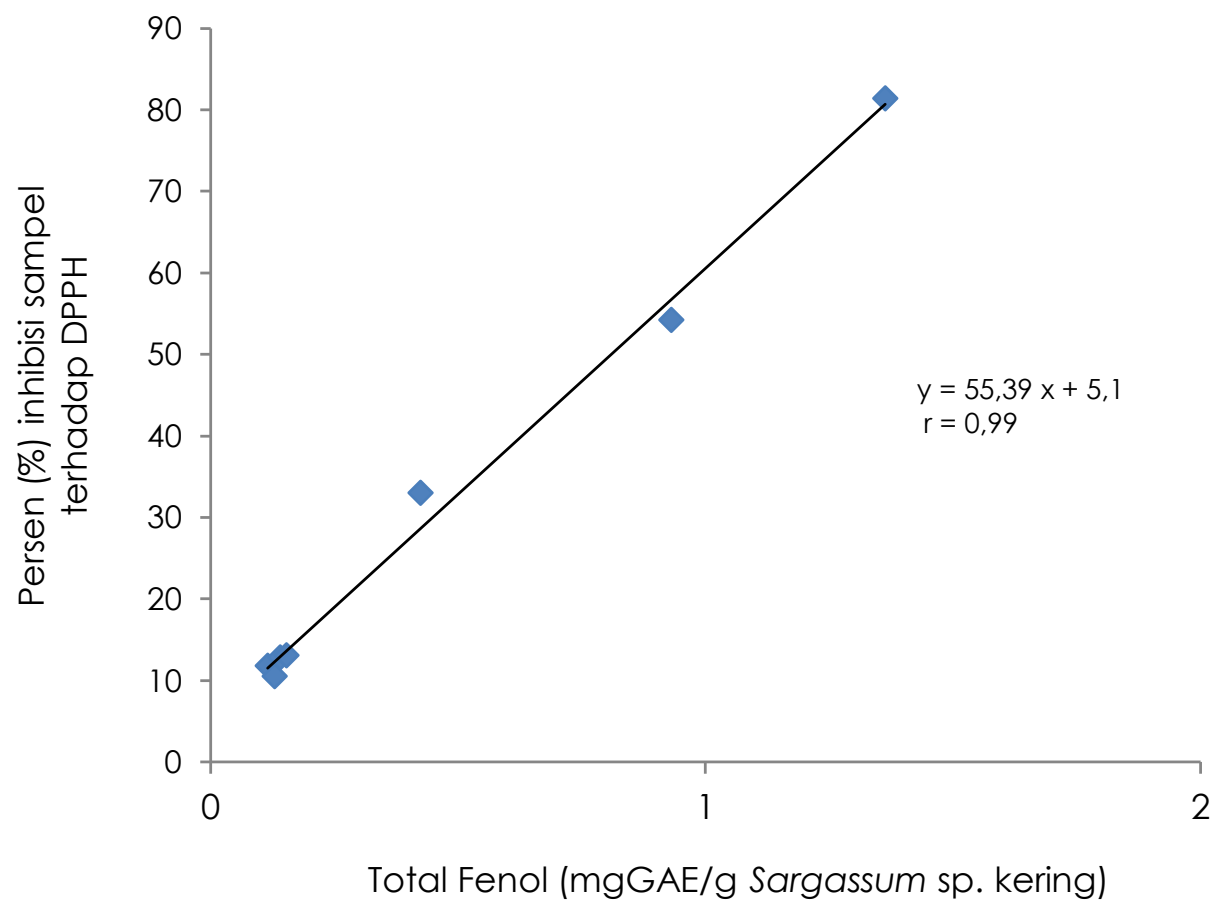

Gambar 3. Pengaruh TPC terhadap Inhibisi (\%) DPPH Filtrat Sargassum sp.:(1) metanol teknis ; (2) metanol pa. ; (3) etanol teknis ; (4) etanol pa. ; (5) methanol teknis 50\%; (6) air panas/infused ; (7) perebusan 30 menit

Senyawa fenolik dari genus ini memiliki kepolaran medium (semi polar sampai polar). Pendapat ini didukung oleh Bambang (2013), senyawa fenolik
Sargassum sp. lebih banyak larut di etanol dibanding etil asetat dan n-heksana. Senyawa fenolik makroalga, termasuk alga coklat menunjukkan beberapa bioaktivitas 
seperti antioksidan, antiradical, antialergi, antiradang, dan antiradiasi UV (Berthon et. al., 2017). Fungsi lainnya adalah sebagai penghambat pelepasan histamin ketika terjadi peradangan kulit, sehingga mampu mencegah terjadinya dermatitis atopic (Heo et al., 2009).

Fungsi senyawa fenolik sebagai anti oksidan bisa dilihat dari kemampuan senyawa tersebut sebagai penangkal radikal bebas (free radical scavenging). Semakin tinggi persen inhibisi terhadap radikal bebas sintetis (DPPH), semakin besar potensi antioksidannya. Filtrat air (metode perebusan) menghasilkan potensi antioksidan tertinggi $(81,35 \pm 0,42 \%)$. Jika diekivalenkan dengan kurva standar asam ascorbat, maka setara dengan $0,37 \pm 0,01$ $\mathrm{mg} / \mathrm{g}$ Sargassum sp. kering

Hasil penelitian ini menunjukkan bahwa filtrat air memiliki potensi antioksidan tertinggi. Penelitian Kuda et al. (2005) juga sama, ekstrak air alga coklat berpotensi antioksidan lebih tinggi dibanding ekstrak etanol. Secara mendasar terdapat hubungan/korelasi antara kandungan polifenol dan bioaktivitas penangkal radikal bebas. Heo et al. (2009) menyatakan polifenol Sargassum sp. adalah senyawa phlorotannin, yang merupakan oligomer dari phloroglucinol (fucol, phlor-ethol, dan eckol)

Total fenolik dari Sargassum sp. berkorelasi positif terhadap potensi antioksidan (Tao et al., 2009; Luo et al., 2010). Peningkatan konsentrasi TPC meningkatkan persentase inhibisinya terhadap radikal bebas, jadi potensi antioksidannya tergantung konsentrasi.

Korelasi (Pearson correlation)antara variabel TPC sampel Sargassum sp. dan persentase inhibisinya terhadap DPPHsangat kuat. Nilai korelasi positif yang mendekati 1 menunjukkan bahwa TPC memberi sumbangan yang sangat tinggi terhadap potensi antioksidan alga coklat tersebut.

\section{KESIMPULAN}

Filtrat air Sargassum sp. (metode perebusan 30 menit) memiliki kandungan fenol terbesar, yaitu: 1,36 $\pm 0,01 \mathrm{mgGAE} / \mathrm{g}$ berat kering. Persentase inhibisi radikal bebasnya (DPPH) juga paling besar, yaitu : $81,35 \pm 0,42 \%$. Senyawa fenoliknya cenderung bersifat polar dan lebih banyak terlarut di air dibanding pelarut alkohol. Pengaruh variabel bebas TPC terhadap variabel terikat inhibisi DPPH sesuai dengan persamaan regresi liniernya: $y=55,39 x+$ $5,1(r=0,99)$.

\section{UCAPAN TERIMA KASIH}

Penulis mengucapkan terima kasih kepada reviewer dan semua pihak yang telah membantu dalam penyelesaian penulisan karya ilmiah ini.

\section{DAFTAR PUSTAKA}

Agatonovic-Kustrin, S, D. W. Morton, and P. Ristivojevic. 2016. Assessment of Antioxidant Activity in Victorian Marine Algal Extracts Using High Performance Thin-Layer Chromatography and Multivariate Analysis. Journal of Chromatography A., 1468: 228-35.

Bambang, B. S, S. Kumalaningsih, Susinggih $W$ and Hardoko. 2013.Polyphenol Content and Antioxidant Activities of Crude Extract from Brown Algae by Various Solvents. J. Life Sci. Biomed., 3(6): 439-443

Berthon, J., R. Nachat-Kappes, M. Bey, Jean-Paul C., I. Renimel, and E. Filarire. 2017. Marine Algae as Attractive Source to Skin Care. Free Radical Research, 51 (6): 555-567.

Fitton, H. J, T. Oddie, D. Stringer, and S. K. Marinova. 2016. Marine Plant Extracts Offer Superior Dermal Protection $\mathrm{OH}$. (March): 51-54.

Heo, S.J., Ko S.C., Cha S.H., Kang D.H. Park H,S., and Choi Y. Effect of Phlorotannins isolated from Ecklonia cava on Melanogenesis and Their Protective Effect Against Photooxidative Stress Induced by UV-B Radiation. Toxicol. in Vitro, 23 : 11231130

Hwang, Pai-An, Chwen-Herng W., Shu-Yun G., Shih-Yung $C_{\text {., }}$ and Deng-Fwu $H$. 2010. Antioxidant and ImmuneStimulating Activities of Hot-Water Extract from Seaweed Sargassum 
Hemiphyllum. Journal of Marine Science and Technology, 18(1): 41-46.

Ismail, A., Hong T.S., Antioxidant Activity of Selected Commercial Seaweeds. Mal. J. Nutr., 8 : 167-177

Kuda T., Tsunekawa M., Goto H., Araki Y. 2005. Antioxidant Properties of Four Edible Algae Harvested in The Noto Peninsula Japan. J. Food Comp. Anal., $18:$ 625-633.

Liyana-Pathirana, C., Shahidi F. Optimization ofextraction ofphenolic compounds from wheat using response surface methodology. Food Chem., 93:47-56.

Lim, S.N, Cheung P.C, Ooi V.E, and Ang P.O. 2002. Evaluation of antioxidative activity of extracts from a brown seaweed, Sargassum siliquastrum. J Agric Food Chem. 50(13):3862-3866.

Luo, H. Y., Bin W., Chun-Guang Y., You-le Q. and Chuan-ling S. 2010. Evaluation of antioxidant activities of five selected brown seaweeds from China. Journal of Medicinal Plants Research, 4(18) : 2557-2565,

Machu, L., L. Misurcova, J. V. Ambrozova, J. Orsavova, J. Mlcek, J. Sochor and T. Jurikova. 2015. Phenolic Content and Antioxidant Capacity inAlgal Food Products. Molecules, 20: $1118-1133$

Ozgun, S., F. Turan. 2015. Biochemical composition of some brown algaefrom Iskenderun Bay, the northeastern Mediterranean coast of Turkey. J. Black Sea/Mediterranean Environment, 21 (2): 125-134
Samee H, Li ZX, Lin H, Khalid J, and Guo, YC. 2009. Antiallergic effects of ethanol extracts from brown seaweeds. Journal of Zhejiang University Science B.,10(2):147-153

Spigno, G., Tramelli L., and De Faveri D. M. 2007. Effects of extraction time, temperature and solvent on concentration and antioxidant activity of grape marc phenolics. J. of Food Engine., 81 (1): 200-208.

Tao W., Rosa, Gudrun A. 2009. Total Phenolic Coumpound, Radical Scavenging and Metal Chelation of Extract from Iceland Seaweeds. Food Chem., $116: 240-248$.

Uppala, L. 2015. A Review on Active Ingredients from Marine Sources Used in Cosmetics. SOJ Pharm Phamr Sci., 2(3): 1-3.

Wai, C., Foong F., Chun Wai H., Wilson T. L. Y., Faridah A., and Chin P. T. 2015. Effects of Phenolic Antioxidants Extraction from Four Selected Seaweeds Obtained from Sabah PrePrints DOI : 10.7287/peerj.prepri nts.1249v1

Wang, H. M. D., C. C. Chen, P. Huynh, and J. S. Chang. 2015. Exploring the Potntial of Using Algae in Cosmetics. Bioresource Technology., 184:355-362

Wei Y., Li Z., Hu Y., Xu Z. Inhibition of Mouse Liver Lipid Peroxidation by Hight Molecular Weight Phlorotannins from Sargassum kjellmanianum. J. Appl. Phycol., $15: 507-511$. 